\title{
Advanced Fuels for LWRs: Fully-Ceramic Microencapsulated and Related Concepts FY 2012 Interim Report
}

R. Sonat Sen

Brian Boer

John D. Bess

Michael A. Pope

Abderrafi M. Ougouag

March 2012

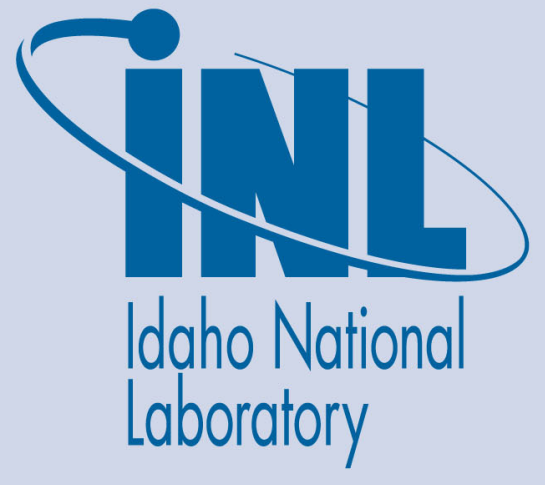

The INL is a U.S. Department of Energy National Laboratory operated by Battelle Energy Alliance 
INL/EXT-12-25122

FCRD-FUEL-2012-000079

\title{
Advanced Fuels for LWRs: Fully-Ceramic Microencapsulated and Related Concepts FY 2012 Interim Report
}

\author{
R. Sonat Sen \\ Brian Boer \\ John D. Bess \\ Michael A. Pope \\ Abderrafi M. Ougouag
}

March 2012

\section{Idaho National Laboratory \\ Fuel Cycle Research \& Development Idaho Falls, Idaho 83415}

http://www.inl.gov

Prepared for the

U.S. Department of Energy

Office of Nuclear Energy

Under DOE Idaho Operations Office

Contract DE-AC07-05ID14517 


\section{DISCLAIMER}

This information was prepared as an account of work sponsored by an agency of the U.S. Government. Neither the U.S. Government nor any agency thereof, nor any of their employees, makes any warranty, expressed or implied, or assumes any legal liability or responsibility for the accuracy, completeness, or usefulness, of any information, apparatus, product, or process disclosed, or represents that its use would not infringe privately owned rights. References herein to any specific commercial product, process, or service by trade name, trade mark, manufacturer, or otherwise, does not necessarily constitute or imply its endorsement, recommendation, or favoring by the U.S. Government or any agency thereof. The views and opinions of authors expressed herein do not necessarily state or reflect those of the U.S. Government or any agency thereof. 


\section{Co-Authors:}

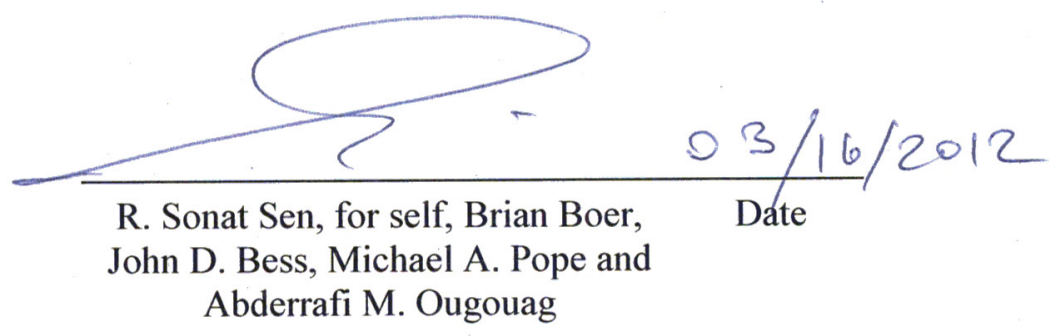

Reviewed by:

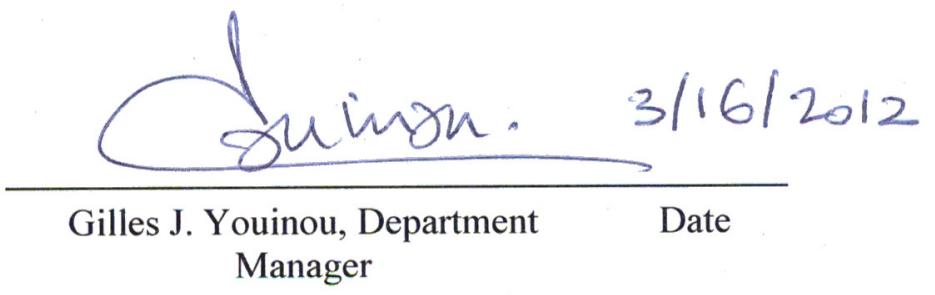

\section{Concurred by:}

Co-Author and Work Package Manager

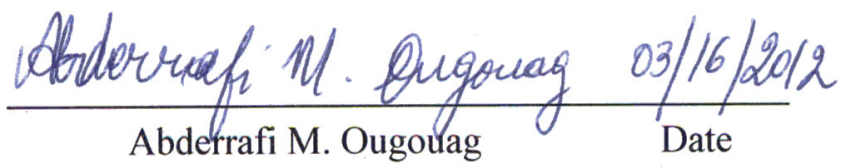




\section{SUMMARY}

This report summarizes the progress in the Fully Ceramic Microencapsulated Fuels project at Idaho National Laboratory during the first half of fiscal year 2012 (FY2012).

Although this project was at its inception aimed at investigating the Deep Burn concept in various reactors, including LWRS, it has evolved into a project aimed at exploring new fuel concepts for ordinary (i.e., non Deep Burn) LWRs. Specifically, the current focus of this project is on Fully-Ceramic Microencapsulated (FCM) fuel containing low-enriched uranium (LEU) in the form of uranium nitride (UN) fuel kernels in a pressurized water reactor (PWR). $\mathrm{UO}_{2}$ fuel kernels have not been ruled out, and will be examined in later work during FY2012.

Reactor physics calculations confirmed that the FCM fuel containing $500 \mu \mathrm{m}$ diameter kernels of $20 \%$ enriched UN fuel exhibits positive moderator temperature coefficient (MTC) with a fuel compact matching the conventional PWR fuel pellet radius of $4.1 \mathrm{~mm}$. The methodology was also put into place to perform whole-core calculations using DONJON, which can interpolate cross sections from a library generated using the DRAGON lattice transport code. The methodology was validated against MCNP. Comparisons to MCNP were performed on the whole core to confirm the accuracy of the DRAGON/DONJON schemes. A thermal fluid coupling scheme was also developed and implemented in connection with DONJON. This new capability is currently able to iterate between neutron diffusion calculations and thermal fluid calculations in order to update fuel temperatures and cross sections in the course of whole-core calculations.

In the second half of FY2012, reactor physics work will proceed to address more realistic reactor configurations, including whole cores with burnable poisons and soluble boron. The studies will include the tuning of reactivity feedback coefficients to ensure a safe design. In particular, a design will be sought that remedies the problem posed by the positive MTC identified above. The design will also have to result in a negative moderator void coefficient (or at least not positive). The process by which these goals will be achieved is an iterative one of successive adjustments of the burnable poisons configuration and the dissolved boron concentration. In addition to these studies, calculations of departure from nucleate boiling ratio (DNBR) will also be carried out as part of the safety evaluation. Once a startup core is shown to be viable, subsequent reloads will be simulated by shuffling fuel and introducing fresh fuel. These studies will all be carried out using the DONJON methodology described above.

On the subject of fuel performance modeling, the PASTA code has been updated with material properties of uranium nitride (UN) fuel taken from the literature and with the addition of a model for the diffusion and release of volatile fission products from the $\mathrm{SiC}$ matrix material. Preliminary simulations have been performed for both normal conditions and elevated temperatures. The results indicated that the fuel performs well and that the $\mathrm{SiC}$ matrix exhibits good retention of the fission products. The path forward for fuel performance work includes improvement of metallic fission products release from the kernel. Heretofore, results should be considered preliminary and the need for further validation should be recognized.

A final remark pertains to the overall methodology that is presented in this document as well as to elements regarding complementary modeling in support of irradiation planning that was reported on last fiscal year and will be again in the final report at the end of this Fiscal Year. It should be noteworthy that the FCM fuel considered in this study is an obvious candidate for designation as an "accident tolerant fuel." Therefore, the methodology of this and previous reports can be considered a prototype of a future concept-neutral methodology for evaluating the performance of such novel fuel concepts. 


\section{CONTENTS}

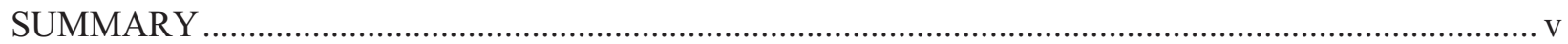

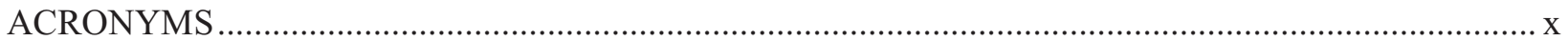

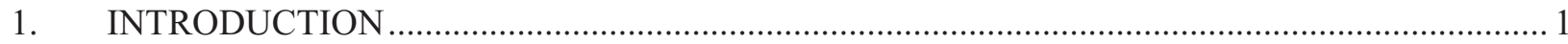

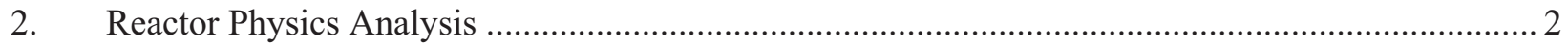

2.1 Objectives of Reactor Physics Analysis....................................................................... 2

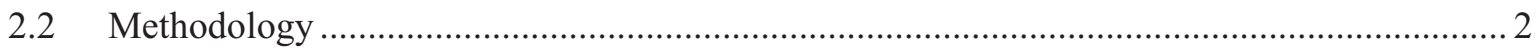

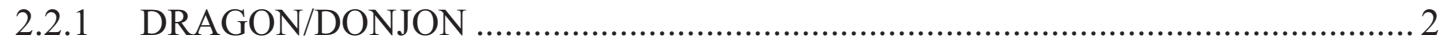

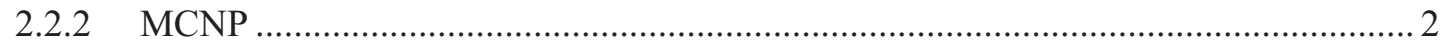

2.3 Description of Baseline Fuel and Core Characteristics................................................ 3

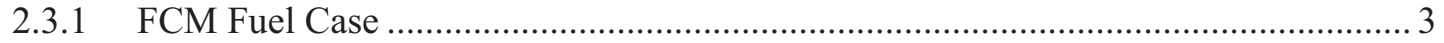

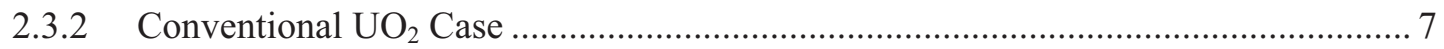

2.4 Studies of Reactivity Coefficients at Lattice Level............................................................ 7

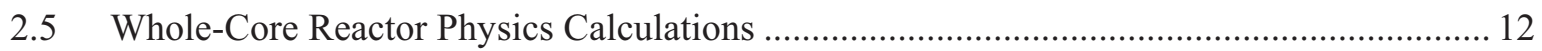

2.5.1 Description of DRAGON/DONJON Calculation Sequence ..................................... 12

2.5.2 Comparison of DRAGON/DONJON Results to MCNP ......................................... 12

2.6 Thermal-Fluid Coupling with DONJON …......................................................................... 15

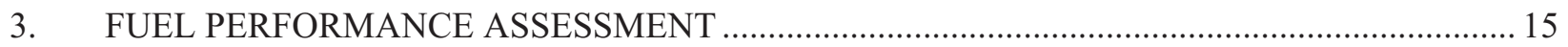

3.1 Objectives of Fuel Performance Work ........................................................................ 15

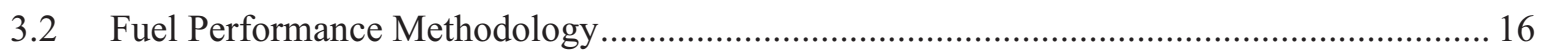

3.2.1 Material Properties of Uranium-mononitride............................................................ 16

3.2.2 Fission Gas Release of Uranium-mononitride ....................................................... 17

3.2.3 Fission Product Transport in the Particle Coatings and the SiC-matrix ................... 18

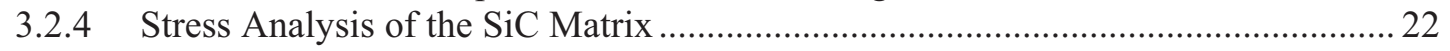

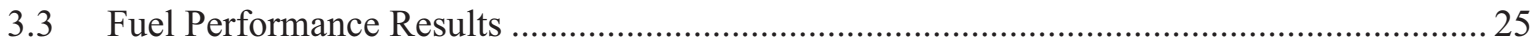

3.3.1 Performance of the reference design under Normal operating conditions ................ 25

3.3.2 Performance of the reference design during elevated temperatures..........................28

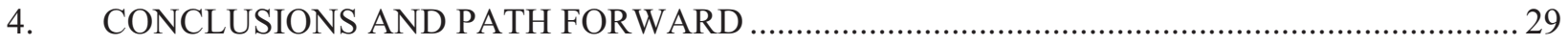

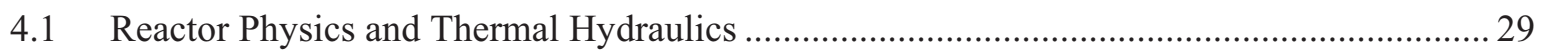

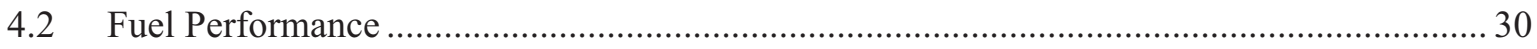

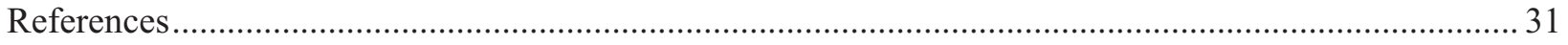

\section{FIGURES}

Figure 2-1. Cross section of a single layer of TRISO particles within the $\mathrm{SiC}$ fuel matrix........................ 3

Figure 2-2. Arrangement of fuel pins and guide tubes in fuel assembly. ............................................. 6

Figure 2-3. Diagram of core layout of PWR used in this analysis (dimensions in $\mathrm{cm}$ ).......................... 6

Figure 2-4. $\mathrm{K}_{\infty}$ versus burnup in EFPD and $\mathrm{GWd}$ /tonne for $0.41 \mathrm{~cm}$ radius fuel pellet FCM fuel............. 8 
Figure 2-5. Doppler coefficient versus burnup for $0.41 \mathrm{~cm}$ radius FCM fuel pellet.................................9

Figure 2-6. Soluble boron worth versus burnup for $0.41 \mathrm{~cm}$ radius FCM fuel pellet...............................9

Figure 2-7. Moderator temperature coefficient versus burnup for $0.41 \mathrm{~cm}$ radius FCM fuel pellet.......... 10

Figure 2-8. MTC v. burnup for a range of FCM fuel pellet radii given in legend in mm........................ 10

Figure 2-9. Fresh fuel $\mathrm{k}_{\infty}$ versus FCM fuel pellet radius................................................................ 11

Figure 2-10. Fresh fuel $\mathrm{k}_{\infty}$ versus hydrogen-to-heavy metal ratio for FCM fuel pellet radius variation.

Figure 2-11. Diagram showing equivalent Cartesian representation (hashed) of reflector (shaded gray).

Figure 3-1. Fission gas release as a function of the temperature in UN fuel for several burnup levels (equation (1), [7]).

Figure 3-2. Diffusion coefficients $\left(\mathrm{m}^{2} / \mathrm{s}\right)$ of fission products in HTR graphite matrix material and $\mathrm{SiC}$ as a function of the temperature, [10].

Figure 3-3. Stresses (principal and effective) in the SiC-matrix as a function of the radial position at a power level of $200 \mathrm{~W} / \mathrm{cm}$.

Figure 3-4. Maximum equivalent stress in the $\mathrm{SiC}$-matrix as a function of the linear power.

Figure 3-5. Tangential stresses in the coating layers and the buffer pressure during irradiation of the particle (with reference dimensions).

Figure 3-6. Failure probability (fabrication, decomposition, stress, and total) and kernel FGR fraction as a function of the burnup for the particle with the reference coating dimensions. .26

Figure 3-7. Release fractions of relevant metallic fission products and the fission gas released fraction from the fuel kernel and the pellet during normal operation for graphite matrix material (a); and $\mathrm{SiC}$ matrix material (b).

Figure 3-8. Release fractions of relevant metallic fission products and the fission gas released fraction from the fuel kernel and the pellet as a function of the temperature for a burnup level of $10 \%$ FIMA.

Figure 3-9. Release fractions of relevant metallic fission products and the fission gas released fraction from the fuel kernel and the pellet as a function of the temperature for a burnup level of $22 \%$ FIMA.

\section{TABLES}

Table 2-1. Characteristics of LWR assembly and core initially analyzed. 4

Table 2-2. Description of TRISO particles and compact matrix in reference FCM fuel........................... 5

Table 2-3. Number densities for 19.9 w/ enriched uranium nitride fuel kernels. ...................................... 5

Table 2-4. Fuel number densities in conventional $\mathrm{UO}_{2}$ case. ............................................................ 7

Table 2-5. Cases run in comparison of DRAGON/DONJON and MCNP in fresh core of conventional $\mathrm{UO}_{2}$ fuel. 
Table 2-6. Cases run in comparison of DRAGON/DONJON and MCNP in fresh core of FCM fuel having $500 \mu \mathrm{m}$ diameter kernels. 14

Table 3-1. Material properties of Uranium-mononitride [6] 16

Table 3-2. Fission products considered in PASTA. Nuclear data from ENDF/B-VII.1 and JEFF3.1 . 18

Table 3-3. SiC material properties used in the stress analysis [14] and typical values for $\mathrm{UO}_{2}$ [12]. 
Advanced Fuels for LWRs: FCM and Related Concepts FY 2012 Interim Report

March 2012 


\section{ACRONYMS}

DB

DNBR

EFPD

FCM

FPs

GWd

LEU

LWR

MCNP

MTC

PASTA

PF

ppm

PWR

TRISO

TRU

UN

$\mathrm{UO}_{2}$
Deep Burn

Departure from Nuclear Boiling Ratio

Effective Full Power Days

Fully Ceramic Microencapsulated

Fission Products

Gigawatt Days

Low Enriched Uranium

Light Water Reactor

Monte Carlo n-Particle transport code

Moderator Temperature Coefficient

PArticle STress Analysis code

Packing Fraction

Parts per million

Pressurized Water Reactor

Tri-isotropic

Transuranics

Uranium nitride

Uranium dioxide 
Advanced Fuels for LWRs: FCM and Related Concepts FY 2012 Interim Report

March 2012 



\section{ADVANCED FUELS FOR LWRS: FCM AND RELATED CONCEPTS FY 2012 INTERIM REPORT}

\section{INTRODUCTION}

The tri-isotropic (TRISO) fuel developed for High Temperature Reactors (HTRs) is known for its extraordinary fission product retention capabilities [1]. Recently, the possibility of extending the use of TRISO particle fuel to Light Water Reactor (LWR) technology, and perhaps other reactor concepts, has received significant attention [2]. In the framework of the Deep Burn (DB) project, once-through burning of transuranic fissile and fissionable isotopes (TRU) in LWRs was investigated [3]. The fuel form for this purpose, known as Fully-Ceramic Micro-encapsulated (FCM) fuel, embodies a concept that borrows the TRISO fuel particle design from high temperature reactor technology, but uses silicon carbide (SiC) as a matrix material rather than graphite. In addition, FCM fuel may also use a cladding made of a variety of possible materials, again including $\mathrm{SiC}$ as an admissible choice. Such a concept in the context of LWRs was proposed by teams led by Venneri [4] for core physics and by Snead [5] for fuel and material considerations.

The focus of this work is on utilization of the FCM fuel concept in a Pressurized Water Reactor (PWR) using low-enriched uranium (LEU) fuel, i.e. less than $20 \%{ }^{235} \mathrm{U}$ by weight. In 2011 , work was performed evaluating this possibility by exchanging conventional $\mathrm{UO}_{2}$ fuel pellets with the FCM fuel compacts without changing assembly geometry. Assembly lattice calculations were performed to evaluate cycle lengths achievable under this constraint. This geometric constraint was shown to lead to unacceptablyshort cycle lengths if $\mathrm{UO}_{2}$ kernels are used. [3] Uranium nitride (UN) fuel was identified as a candidate fuel form due to its high heavy metal density. [6] Uranium oxide $\left(\mathrm{UO}_{2}\right)$ fuel kernels are not to be ruled out, however, but would likely have to be used in conjunction with larger diameter fuel pins in order to compensate for their relatively low heavy metal density. This relaxation of geometric constraints will be investigated in this work as well.

A second focus of this work pertains to fuel performance calculations. Such calculations were performed for the prediction of the performance of UN FCM fuel during static and transient conditions typical of LWRs. The performance of the fuel is quantified by the failure fraction of the TRISO coated fuel particles and the release fraction of gaseous and volatile fission products. For this performance analysis the PArticle STress Analysis code (PASTA) [15] has been updated. The code has been used in the past for the evaluation of coated particle oxide fuel in both HTR and FCM LWR applications.

Section 2 of this report contains interim results of the reactor physics analysis. Section 3 gives interim results on fuel performance analysis. 


\section{Reactor Physics Analysis}

\subsection{Objectives of Reactor Physics Analysis}

The objective of the reactor physics analysis work is to identify a neutronically viable design which uses FCM fuel containing LEU kernels. In previous work, DRAGON (see Section 2.2.1) lattice calculations were used for scoping analyses, primarily investigating the impact of fuel kernel type and size on achievable cycle length. [6] In this work, lattice calculations are again used for initial scoping; this time with focus not only on cycle length, but on key reactivity coefficients. The methodology was also expanded to include whole core calculations using the DRAGON/DONJON code system. This capability was put into place during the first half of FY2012 and validation cases were performed comparing the DRAGON/DONJON whole-core results with results of MCNP calculations.

\subsection{Methodology}

\subsubsection{DRAGON/DONJON}

The DRAGON/DONJON suite of reactor physics codes was selected as the primary analysis tool for this work. DRAGON is an open source lattice physics transport code developed and maintained by École Polytechnique de Montréal[7]. The code incorporates multiple solution methods and allows flexible calculation routes and data manipulation. In particular, it includes a capability for the direct treatment of the double heterogeneity arising from the fuel morphology as dispersed TRISO particles within a fuel matrix [8]. Collision probability calculations were performed using a cross section library generated from ENDF/B- VII.0 and cast in the SHEM-281 energy group structure. [9]

Unit cell depletion calculations were performed to evaluate the FCM fuel. Each type of fuel investigated was depleted based on a flux calculation using a $\mathrm{B}_{0}$ buckling search. Single cell calculations can be informative with regard to the performance of the fuel under consideration, especially when a whole core is loaded with similar fuel. The information is also useful when the core is "zoned" and the fuel under consideration is loaded in only parts of the core. It is then possible to determine when the zone is a driver (i.e., has an infinite multiplication factor, $\mathrm{k}_{\infty}$, greater than 1.0) and when it becomes driven (i.e., at what point the zone has a $\mathrm{k}_{\infty}$ lower than 1.0). The presence of driven zones shortens the cycle i.e, the time between required refueling outages, though they contribute to achieving higher burnup levels. Key reactivity coefficients were calculated at the lattice level by perturbing the conditions at each burnup step.

Whole core calculations using DONJON were also performed. These calculations use cross-sections generated in the DONJON lattice calculations and interpolate within them based on prevailing conditions as specified. Further discussion of this methodology and the generation of cross section libraries are reserved for Section 2.5.1.

\subsubsection{MCNP}

Monte Carlo n-Particle (MCNP) version 5-1.60 calculations were utilized to calculate Eigenvalues for the various test configurations. MCNP is a general-purpose, continuous-energy, generalized-geometry, timedependent, coupled n-particle Monte Carlo transport code. The Evaluated Neutron Data File library, ENDF/B-VII.0, cross section data was also used in this evaluation. The statistical uncertainty in $\mathrm{k}_{\text {eff }}$ in 
these calculations is $\leq 0.00005$. Calculations were performed with 400 cycles with 500,000 neutrons per generation. The $\mathrm{k}_{\text {eff }}$ estimates did not include the first 50 cycles and are therefore the result of 175,000,000 active neutron histories.

Whereas the DRAGON lattice code is capable of direct treatment of the double heterogeneity of TRISO particles within a fuel matrix, MCNP lacks this capability. Therefore, a lattice of TRISO particles must be explicitly specified. To facilitate this, the TRISO particles were modeled in a static hexagonal matrix as shown in Figure 2-1. For the purposes of validation of DRAGON/DONJON calculations for the FCMfueled PWR core, a 44\% packing fraction was used. The hexagonal prisms used to describe the lattice have both a height and flat-to-flat distance of $0.0964852 \mathrm{~cm}$. Each layer contains 55 TRISO particles with 4353 layers along the entire active length of the fuel, providing a total of 239,415 TRISO particles per fuel rod with an effective packing fraction of $44.0095 \%$.

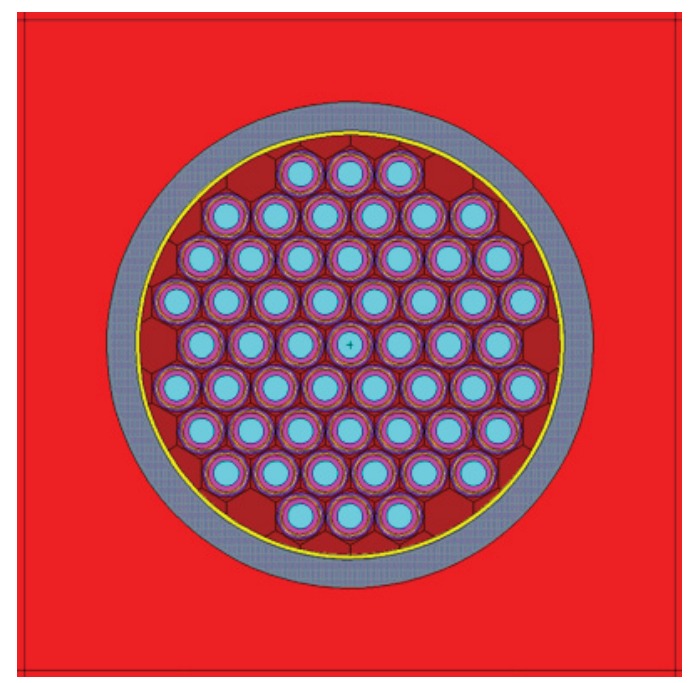

Figure 2-1. Cross section of a single layer of TRISO particles within the SiC fuel matrix.

\subsection{Description of Baseline Fuel and Core Characteristics}

\subsubsection{FCM Fuel Case}

This section provides a description of the baseline characteristics of the fuel and core used for initial calculations of burnup and reactivity coefficients in lattice and whole core models with both the DRAGON/DONJON calculation sequence and with MCNP.

Table 2-1 shows basic information about the PWR core to be used. Many of the parameters were taken from Reference [12]. Fuel pellet and cladding diameters are varied in the analysis (parameters indicated by asterisk in

Table 2-1). In addition to the FCM-fueled PWR, which is the subject of this study, a "conventional" $\mathrm{UO}_{2}$-fueled PWR core was modeled in order to provide a reference against which to compare the results from the FCM cores. Description of the parameters unique to the conventional $\mathrm{UO}_{2}$ fuel is given in Section 2.3.2. The information in

Table 2-1 holds true in either case. These dimensions are assumed to be at hot or cold conditions, neglecting for now the effects of thermal expansion of materials. 
The fuel pellets (or compacts) of the reference FCM case contain TRISO particles embedded in SiC matrix material. The contents and dimensions of the TRISO particle layers are given in Table 2-2.

Table 2-3 gives the nuclide number densities of the $19.9 \mathrm{w} / \mathrm{o}$ enriched UN fuel used in the kernels. With these number densities for UN in FCM fuel having packing fraction (PF) of $44 \%$ and $500 \mathrm{~mm}$ diameter kernels, the effective heavy metal density on a pellet basis is $0.95 \mathrm{~g} / \mathrm{cm}^{3}$. Replacing the UN fuel with $\mathrm{UO}_{2}$ directly with no change to geometry and TRISO PF gives an effective heavy metal density of 0.65 $\mathrm{g} / \mathrm{cm}^{3}$.

The cladding is assumed to be $\mathrm{SiC}$ and the coolant water is assumed to be at a uniform temperature of 585 $\mathrm{K}\left(312^{\circ} \mathrm{C}\right)$ and have a uniform mass density of $0.698 \mathrm{~g} / \mathrm{cm}^{3}$.

Table 2-1. Characteristics of LWR assembly and core analyzed.

\begin{tabular}{|l|c|}
\hline \multicolumn{1}{|c|}{ Parameter } & Value \\
\hline Reactor thermal power $\left(\mathrm{MW}_{\mathrm{th}}\right)$ & 4500 \\
\hline Number of Fuel Assemblies & 241 \\
\hline Active Fuel Height $(\mathrm{m})$ & 4.20 \\
\hline Assembly Pitch $(\mathrm{cm})$ & 21.504 \\
\hline Pin Pitch $(\mathrm{cm})$ & 1.27 \\
\hline Effective pin pitch for single cell calculations $(\mathrm{cm})$ & 1.32 \\
\hline Number of fueled pins per $17 \times 17$ assembly & 264 \\
\hline Number of guide tubes per $17 \times 17$ assembly & 25 \\
\hline Fuel Pellet Diameter $(\mathrm{mm})$ & $8.20^{*}$ \\
\hline Fuel Pin Inner Diameter $(\mathrm{mm})$ & $8.36^{*}$ \\
\hline Fuel Pin Outer Diameter $(\mathrm{mm})$ & $9.50^{*}$ \\
\hline Guide Tube Inner Diameter $(\mathrm{mm})$ & 11.4 \\
\hline Guide Tube Outer Diameter $(\mathrm{mm})$ & 12.3 \\
\hline Average Linear Power $(\mathrm{kW} / \mathrm{m})$ & 16.7 \\
\hline Average Power per Volume of Core $\left(\mathrm{MW}_{\mathrm{th}} / \mathrm{m}^{3}\right)$ & 96.2 \\
\hline Average Power per Volume of Fuel Pellet $\left(\mathrm{W} / \mathrm{cm}^{3}\right)$ & 318 \\
\hline Coolant Inlet Temperature $\left({ }^{\circ} \mathrm{C}\right)$ & 295.6 \\
\hline Coolant Outlet Temperature $\left({ }^{\circ} \mathrm{C}\right)$ & 328.2 \\
\hline Average Coolant Temperature $\left({ }^{\circ} \mathrm{C}\right)$ & 311.9 \\
\hline Coolant Pressure $(\mathrm{MPa})$ & 15.6 \\
\hline Average Coolant Density $\left(\mathrm{kg} / \mathrm{m}^{3}\right)$ & 698 \\
\hline
\end{tabular}

${ }^{*}$ Varied in the analysis reported in Section 2.4 
Table 2-2. Description of TRISO particles and compact matrix in reference FCM fuel.

\begin{tabular}{|l|c|c|}
\hline Layer & $\begin{array}{c}\text { Thickness } \\
(\boldsymbol{\mu \mathbf { m } )}\end{array}$ & $\begin{array}{c}\text { Density } \\
\left(\mathbf{g} / \mathbf{c m}^{\mathbf{3}}\right)\end{array}$ \\
\hline Kernel (UN) & $500^{\dagger}$ & 14.32 \\
\hline Porous Carbon Buffer & 100 & 1.05 \\
\hline Inner Pyrolytic Carbon & 35 & 1.9 \\
\hline $\mathrm{SiC}$ & 35 & 3.18 \\
\hline Outer Pyrolytic Carbon & 40 & 1.9 \\
\hline SiC Matrix & NA & 3.18 \\
\hline
\end{tabular}

Table 2-3. Number densities for $19.9 \%$ enriched uranium nitride fuel kernels.

\begin{tabular}{|l|c|}
\hline Nuclide & $\begin{array}{c}\text { Number Density } \\
\text { (atoms/b·cm) }\end{array}$ \\
\hline U-235 & $6.88622 \mathrm{E}-03$ \\
\hline U-238 & $2.73685 \mathrm{E}-02$ \\
\hline N-14 & $3.42539 \mathrm{E}-02$ \\
\hline
\end{tabular}

The arrangement of fuel pins and guide tubes adopted for the first iterations on this design is shown in Figure 2-2. The darkened circles represent fuel pins and the white circles are guide tubes. These guide tubes are assumed to be filled with water having the same density and boron concentration as coolant when control rods are not inserted. Figure 2-3 shows the layout of the 241-assembly core used in the whole-core analysis. The reflector a "solid" reflector consisting of $95.6 \%$ steel and $4.4 \%$ water by volume. This reflector design is taken from the U.S. EPR design. [12]

\footnotetext{
${ }^{\dagger}$ Fuel kernel diameter.
} 


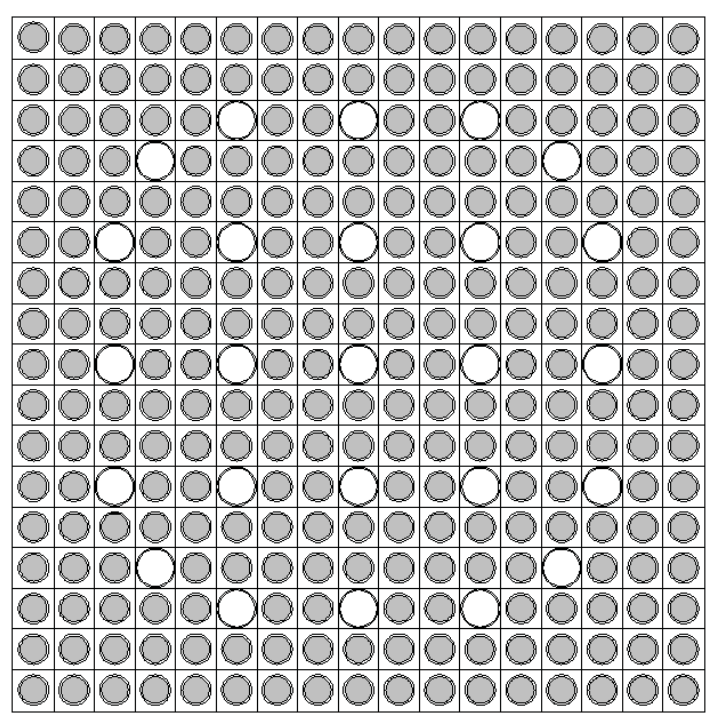

Figure 2-2. Arrangement of fuel pins and guide tubes in fuel assembly.

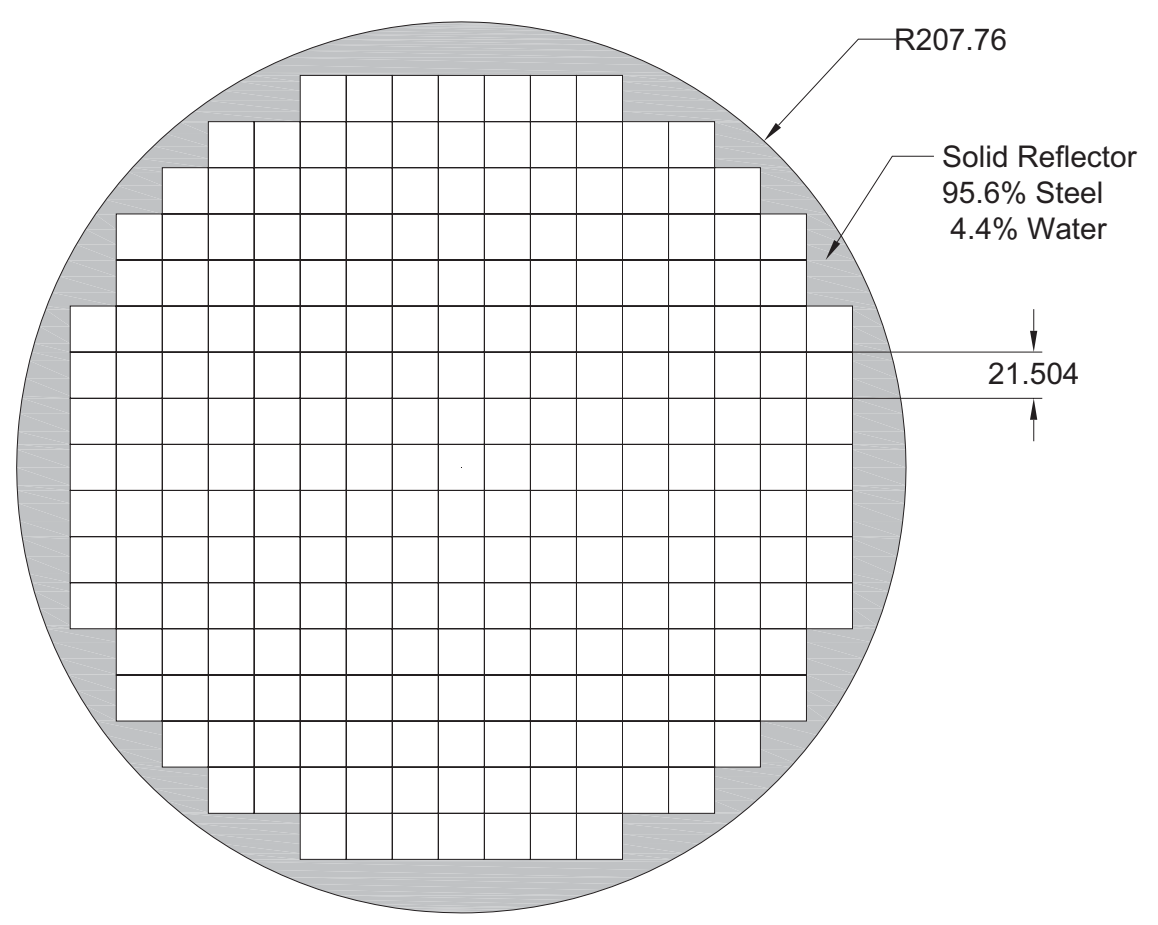

Figure 2-3. Diagram of core layout of PWR used in this analysis (dimensions in $\mathrm{cm}$ ). 


\subsubsection{Conventional $\mathrm{UO}_{2}$ Case}

As mentioned above, a conventional $\mathrm{UO}_{2}$ case of a PWR core was also included for comparison of the two codes to expected results. The $\mathrm{UO}_{2}$ case assumes a fuel mass density of $10.4 \mathrm{~g} / \mathrm{cm}^{3}$ and an enrichment of $4.5 \mathrm{w} / \mathrm{o}^{235} \mathrm{U}$. Table 2-4 shows the nuclide number densities used in this fuel. The fuel compacts from before are simply replaced with solid $\mathrm{UO}_{2}$ pellets having this composition. Aside from this change, the cases are identical. This fuel has a heavy metal density of $9.2 \mathrm{~g} / \mathrm{cm}^{3}$.

Table 2-4. Fuel number densities in conventional $\mathrm{UO}_{2}$ case.

\begin{tabular}{|l|c|}
\hline Nuclide & $\begin{array}{c}\text { Number Density } \\
\text { (atoms/b·cm) }\end{array}$ \\
\hline U-235 & $1.056 \mathrm{E}-03$ \\
\hline U-238 & $2.215 \mathrm{E}-02$ \\
\hline O-16 & $4.461 \mathrm{E}-02$ \\
\hline
\end{tabular}

\subsection{Studies of Reactivity Coefficients at Lattice Level}

The initial case of simply replacing the $\mathrm{UO}_{2}$ pellets of conventional PWR fuel with the UN FCM fuel compacts described in Table 2-2 and

Table 2-3 is first evaluated in this section by performing lattice depletion calculations with DRAGON. At each depletion step, reactivity coefficients are calculated.

For each case, fuel is depleted based on postulated exposure to a flux resulting from a calculation that uses a $\mathrm{B}_{0}$ buckling search. At each depletion step, several perturbations on the unit cell are performed for calculation of the various reactivity coefficients. The parameters calculated at each burnup step in each case are:

- Moderator Temperature Coefficient (MTC) - This is computed by increasing the water coolant temperature by $5^{\circ} \mathrm{C}$ and adjusting the density accordingly. Results are reported in $\mathrm{pcm} /{ }^{\circ} \mathrm{C}$. In this work, this is performed without any soluble boron in the coolant. With the addition of enough soluble boron to make the reactor critical, the MTC would be made more positive. Calculation of MTC with this critical boron concentration is an important part of the assembly design that will be addressed at a later time.

- Doppler Coefficient - This is calculated by increasing the temperature of the fuel by $50^{\circ} \mathrm{C}$ and recomputing the flux and effective multiplication factor. In the case of the solid pellet fuel (MOX and $\mathrm{UO}_{2}$ cases), there is only one temperature to be used in the fuel. In the case of the FCM fuel with its doubly-heterogeneous geometric details, the problem is simplified by setting equal all temperatures in the TRISO particles (and its layers) and in the SiC matrix. The Doppler coefficient is thus calculated by raising all temperatures congruently and uniformly. This simplification may be relaxed in later work as more sophisticated heat transfer models are integrated into the calculations.

- Soluble Boron Worth - This is calculated by adding $1000 \mathrm{ppm}$ of natural boron $\left(19.9 \% / 0{ }^{10} \mathrm{~B}\right)$ to the coolant and recalculating the flux and effective multiplication factor. Results are presented in $\mathrm{pcm} / \mathrm{ppm}$. 
In all of the above calculations, reactivity differences in pcm are calculated by taking the difference in $\mathrm{k}_{\infty}$ and dividing by the nominal $\mathrm{k}_{\infty}$, i.e.,

$$
k_{\text {pert }}=\frac{k_{\text {pert }}-k_{\text {nom }}}{k_{\text {nom }}}
$$

Where $k_{\text {pert }}$ is the perturbed $k_{\infty}$ (e.g., high temperature, altered water conditions, or 1000 ppm boron) and $k_{\text {nom }}$ is the nominal $k_{\infty}$.

Self-shielding calculations are performed for the nominal case and for each additional perturbed case at each burnup step. Though this may not be necessary for all of the smaller perturbations, the small size of the modeled domain allows this to be carried out without incurring an excessive computational burden.

Figure 2-4 shows $\mathrm{k}_{\infty}$ versus burnup in both effective full power days (EFPD) and GWd/tonne heavy metal for case of FCM fuel having UN kernels and the same size pellet and cladding as conventional $\mathrm{UO}_{2}$ fuel ( $8.2 \mathrm{~mm}$ diameter fuel pellet). This shows that $\mathrm{k}_{\infty}$ crosses 1.0 at approximately 400 days. If one assumes a linear reactivity model with 3-batch reloading, this would lead to a cycle length of approximately a halfyear in duration. Figure 2-5 shows Doppler coefficient versus burnup for the same fuel during depletion, Figure 2-6 shows soluble boron worth during depletion, and Figure 2-7 shows MTC versus burnup for the nominally-sized FCM fuel. Figure 2-7 indicates that the fuel has a positive MTC throughout burnup. This is a result of the very low heavy metal loading an overmoderated condition of the fuel. Since depletion lowers the heavy metal content further, the system becomes more overmoderated and MTC becomes more positive with burnup.

Figure 2-8 shows MTC versus burnup for FCM fuel having various fuel pellet radii given in mm in the legend. The cladding thickness was held constant for this variation. This shows that increasing the pellet diameter reduces the MTC to negative values. It appears from this data that a pellet radius in the range of 4.5 to $5.0 \mathrm{~mm}$ may give acceptable MTC during burnup. This increase in fuel mass will also bring about an increase in reactivity-limited burnup.
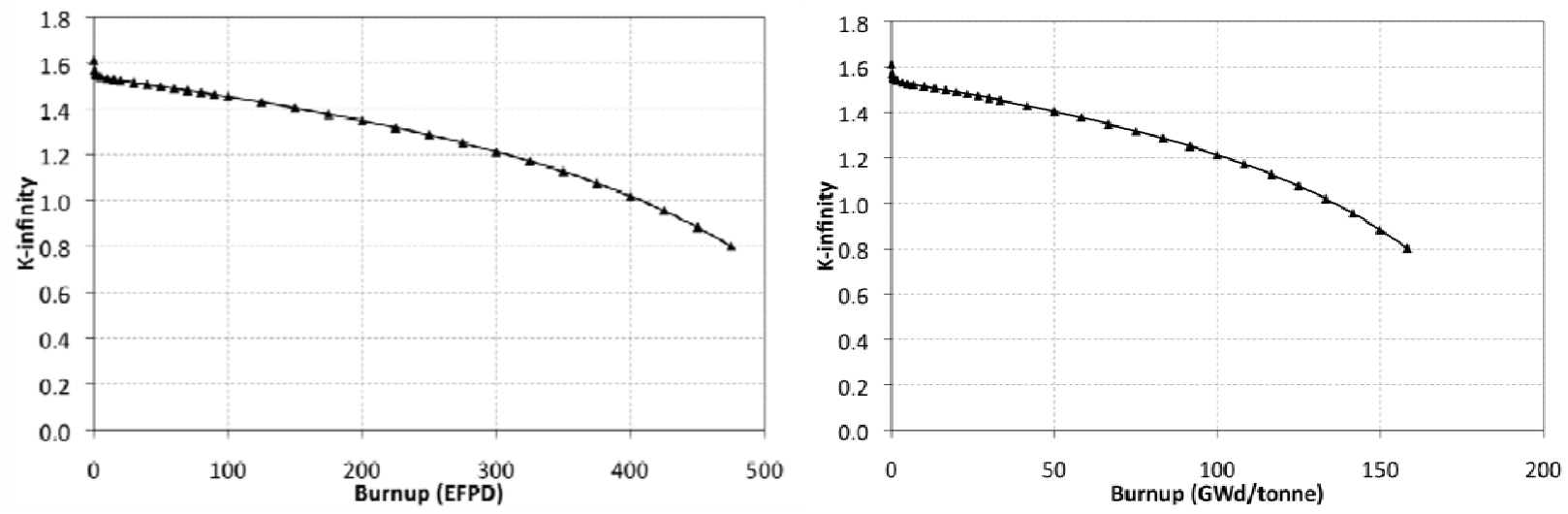

Figure 2-4. $\mathrm{K}_{\infty}$ versus burnup in EFPD and $\mathrm{GWd} /$ tonne for $0.41 \mathrm{~cm}$ radius fuel pellet FCM fuel. 


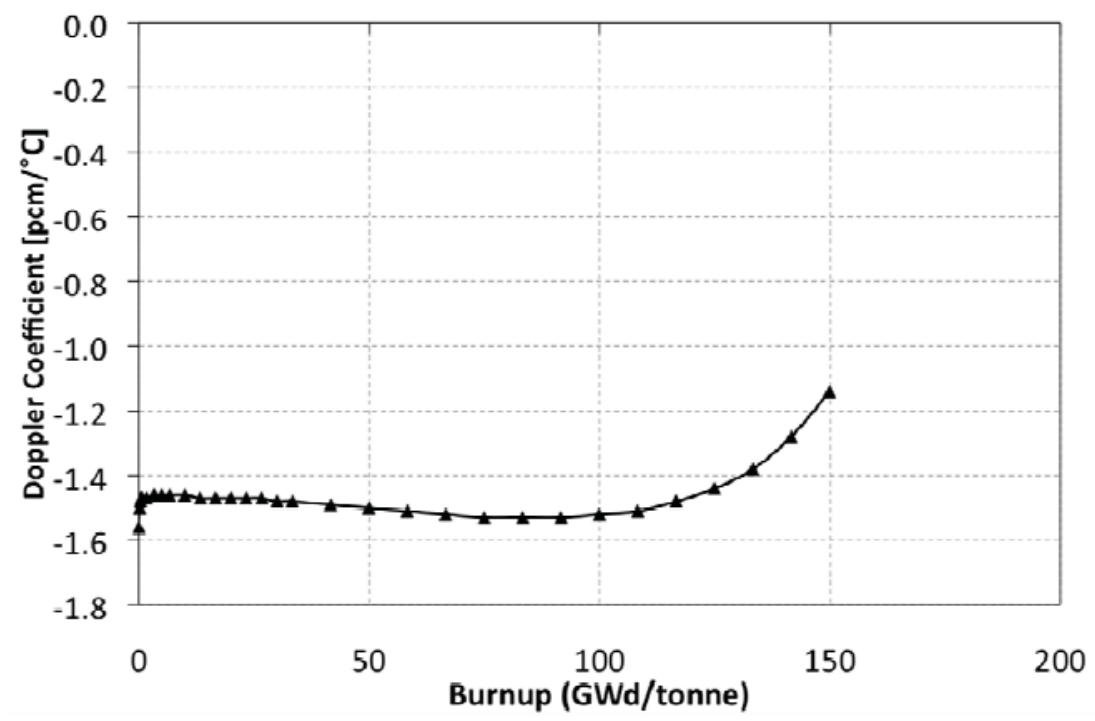

Figure 2-5. Doppler coefficient versus burnup for $0.41 \mathrm{~cm}$ radius FCM fuel pellet.

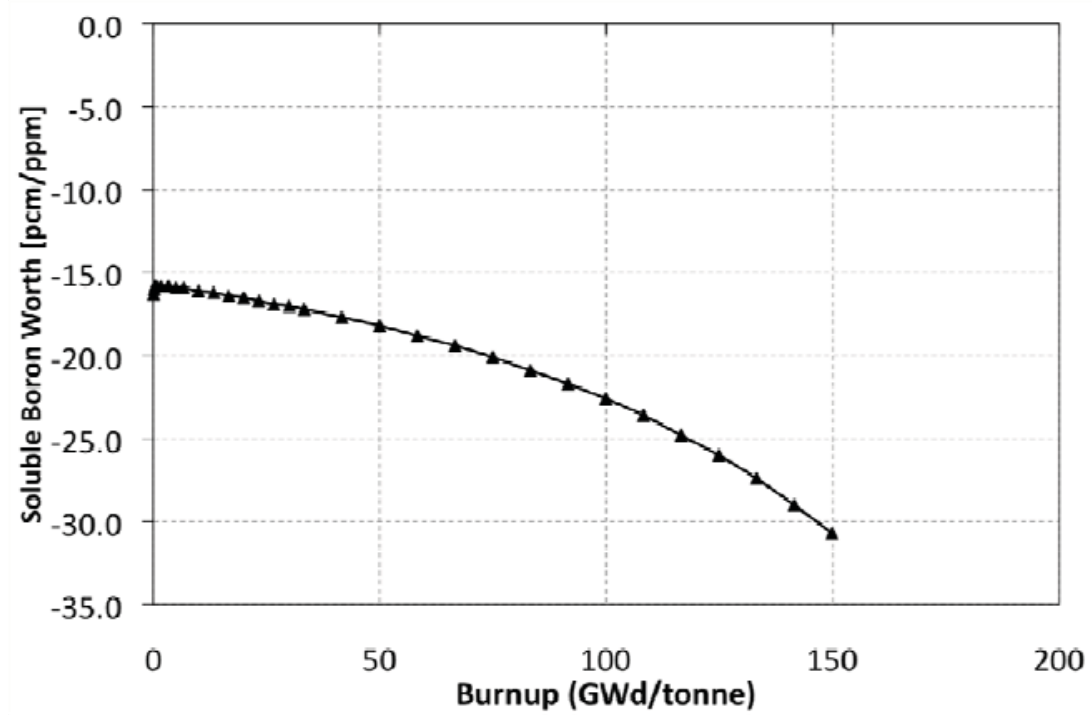

Figure 2-6. Soluble boron worth versus burnup for $0.41 \mathrm{~cm}$ radius FCM fuel pellet. 


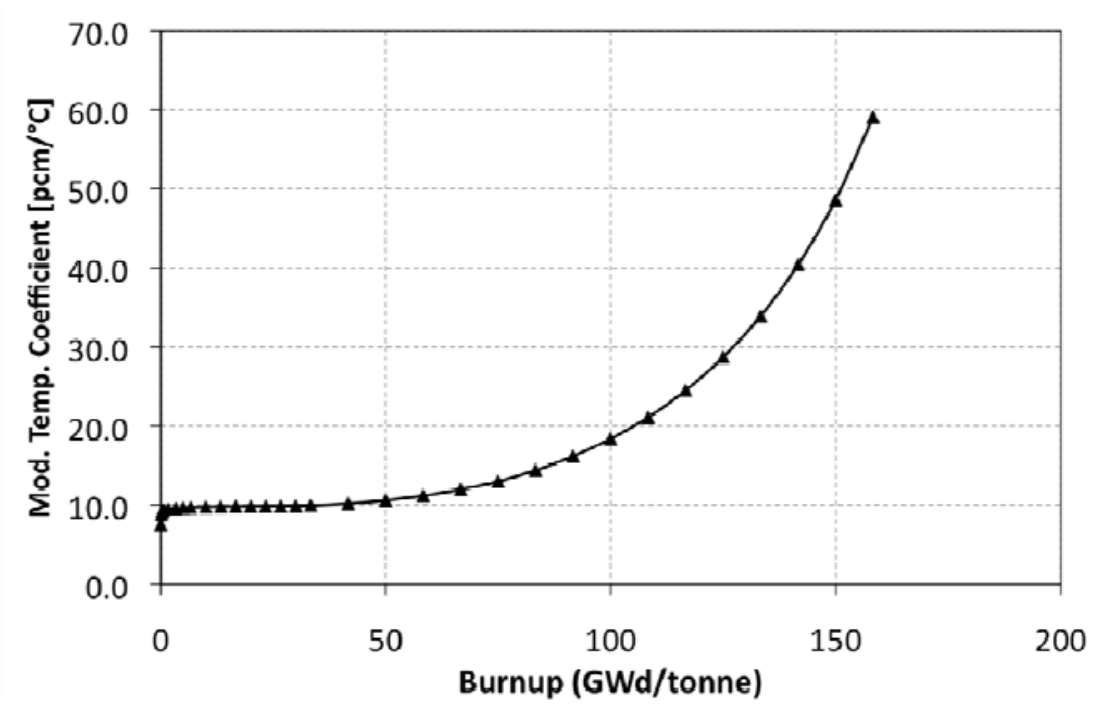

Figure 2-7. Moderator temperature coefficient versus burnup for $0.41 \mathrm{~cm}$ radius FCM fuel pellet with no soluble boron.

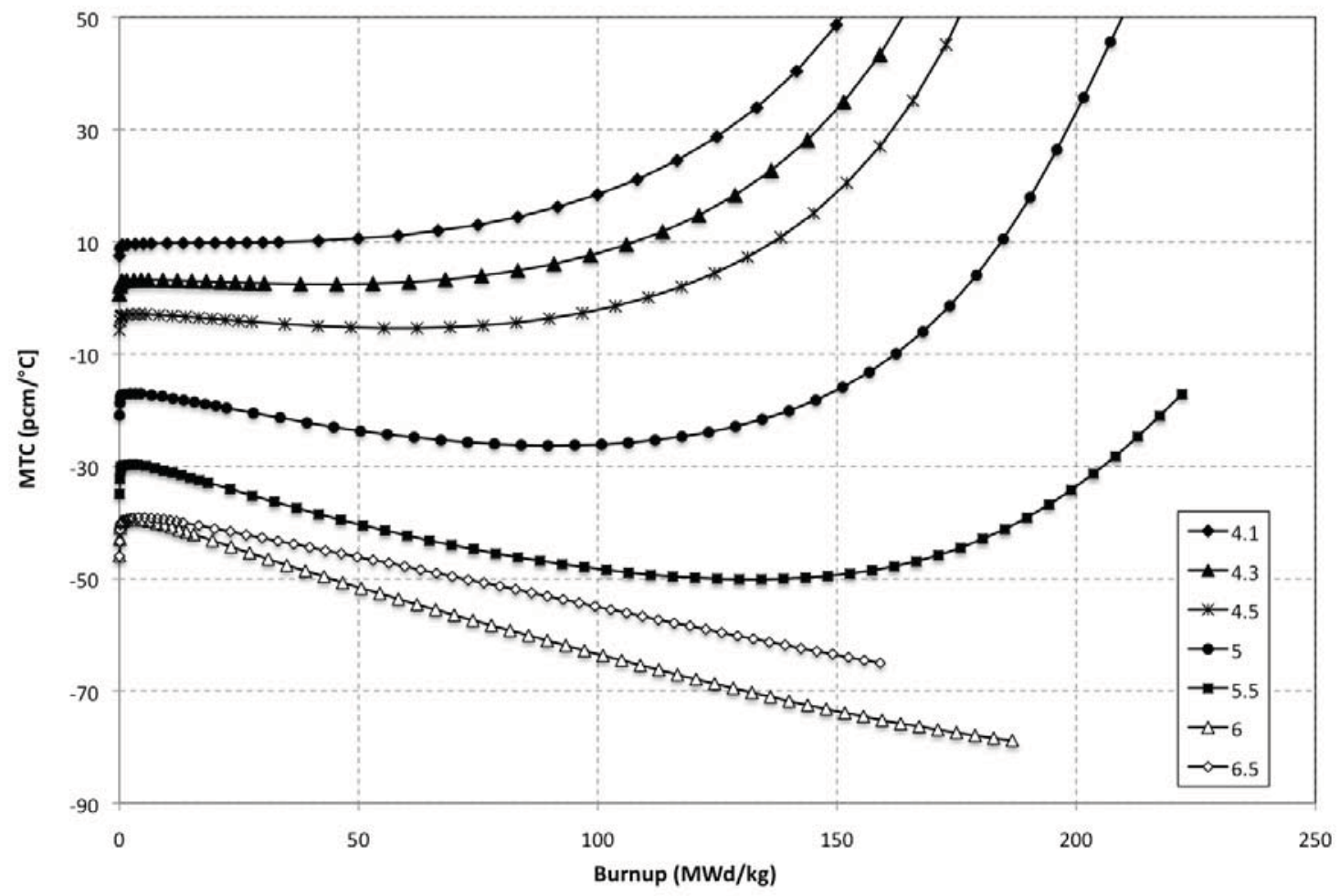

Figure 2-8. MTC with no soluble boron v. burnup for a range of FCM fuel pellet radii given in legend in $\mathrm{mm}$. 
Figure 2-9 shows $\mathrm{k}_{\infty}$ versus FCM fuel pellet radius for the FCM fuel. Figure 2-10 shows the same data reformulated to be a function of hydrogen-to-heavy metal ratio. The conventional $4.1 \mathrm{~mm}$ radius pellet is indicated along with a $0.5 \mathrm{~cm}$ radius pellet, a size which no longer gives overmoderated conditions. Using the same calculation, conventional $\mathrm{UO}_{2}$ fuel would have a $\mathrm{H} / \mathrm{HM}$ value of 2.7. This data provides verification that overmoderation is indeed the cause for the positive MTC in the original fuel size and gives guidance as to the range of fuel sizes that may give acceptable MTC values. It should be noted, however, that changing fuel pin diameter will impact thermal hydraulic performance, including critical heat flux, and safe operation must be verified with respect to these metrics.

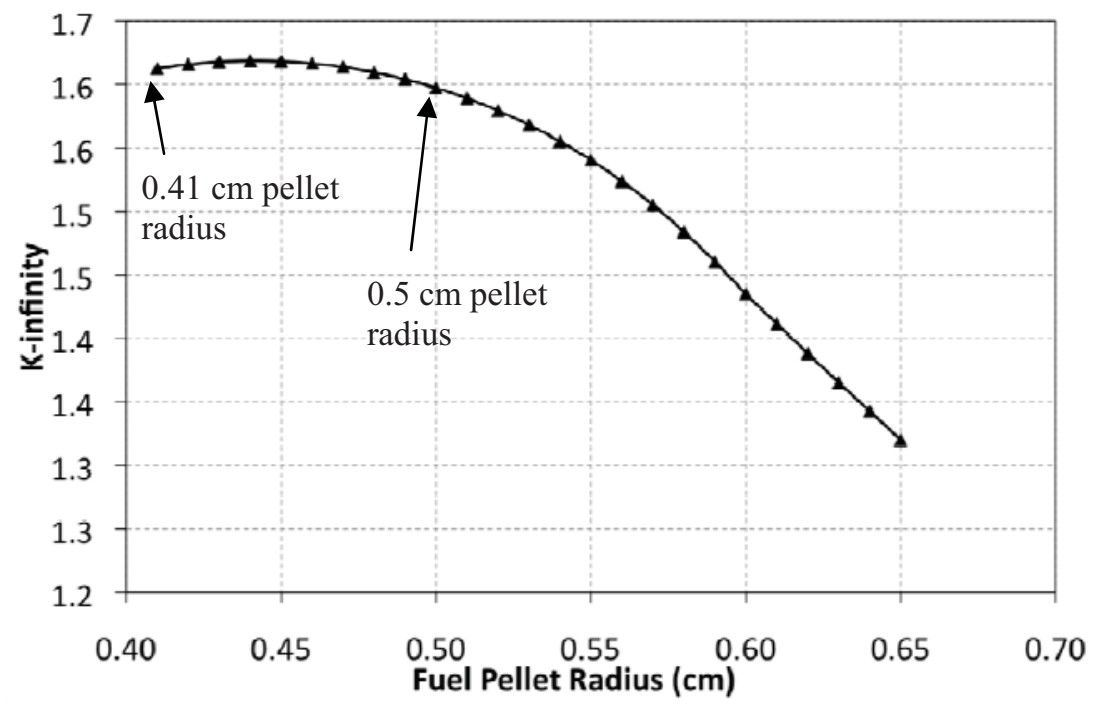

Figure 2-9. Fresh fuel $\mathrm{k}_{\infty}$ versus FCM fuel pellet radius.

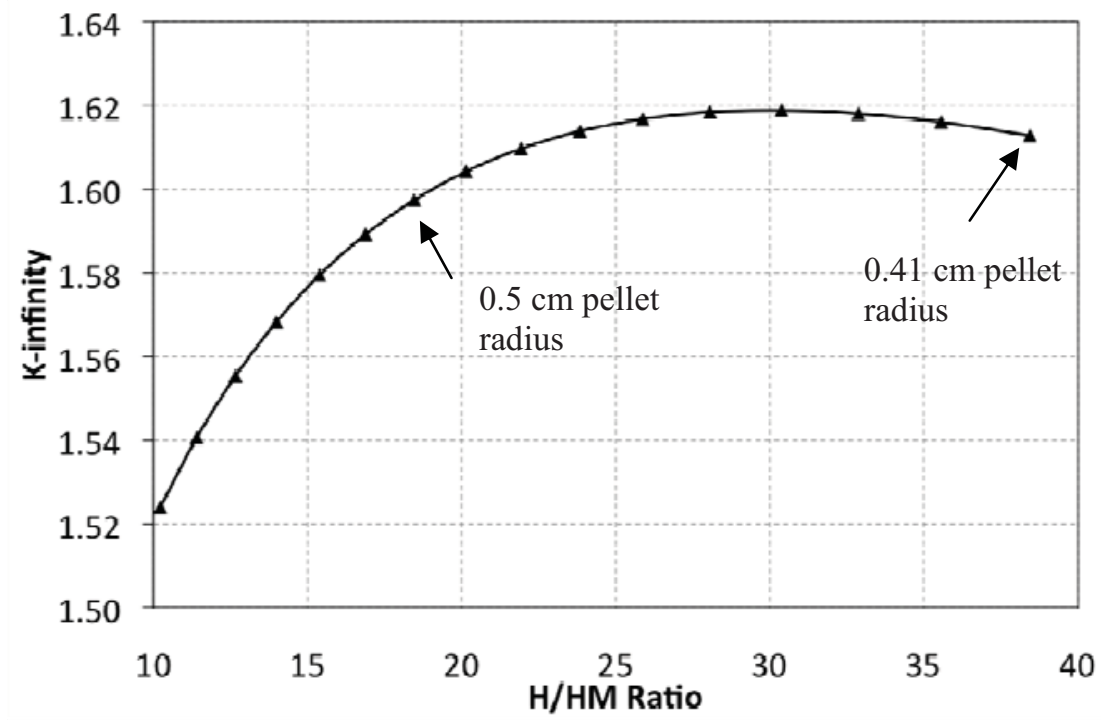

Figure 2-10. Fresh fuel $\mathrm{k}_{\infty}$ versus hydrogen-to-heavy metal ratio for FCM fuel pellet radius variation. 


\subsection{Whole-Core Reactor Physics Calculations}

\subsubsection{Description of DRAGON/DONJON Calculation Sequence}

In order to perform whole-core calculations using DONJON, cross section libraries must first be generated using DRAGON. In order to generate these libraries, depletions were performed by solving for neutron flux using a $\mathrm{B}_{0}$ leakage model in DRAGON as before. At each time step, homogenized 2-group cross sections were calculated and written to a library file. Then at each step, perturbations were performed on fuel temperature, moderator density, soluble boron, and finally the presence of a control rod cluster. These perturbations were each performed individually and the resulting homogenized 2-group cross sections were calculated and written to a library file. The resulting library could then read by DONJON, interpolating between the state variables to match the conditions of interest. For the wholecore solutions, the domain was discretized based on the nodal collocation method and the diffusion equation solved on this mesh.

\subsubsection{Comparison of DRAGON/DONJON Results to MCNP}

Preliminary whole-core calculations were performed in order to compare whole-core results of DRAGON/DONJON calculation sequence to the direct solutions from MCNP. This was performed both with the FCM fuelled core of interest and a conventional $\mathrm{UO}_{2}$ core. In each case, fuel temperatures and moderator densities were used in order to verify the correct interpolation of the libraries by DONJON. Though it is known not to be a viable option, the initial pellet radius $(4.1 \mathrm{~mm})$ was selected for this comparison as a test case only.

Because the exact geometry of the reflector could not be modeled in DONJON, an effective reflector was used. Figure 2-11 shows the geometry of the actual reflector (shaded gray) and the effective reflector as modeled in DONJON (with hashing).

Table 2-5 shows the results of the cases run in comparison of DRAGON/DONJON and MCNP in fresh core of conventional $\mathrm{UO}_{2}$ fuel. The general agreement between the two methods is found to be adequate with slightly and consistently higher $\mathrm{k}_{\text {eff }}$ values calculated by MCNP. Calculations were also performed with and without the reflector present in order to quantify its impact. The greatest discrepancy between MCNP and DONJON occurs at the highest fuel temperature sampled and is less than $0.4 \%$ in $\mathrm{k}_{\text {eff. }}$.

Table 2-6 shows the results of the cases run in comparison of DRAGON/DONJON and MCNP in fresh core of FCM fuel with $4.1 \mathrm{~mm}$ fuel pellet radius. In these comparisons, the agreement between the two codes was found to be excellent. The greatest discrepancy between MCNP and DONJON is less than $0.2 \%$ in $\mathrm{k}_{\text {eff. }}$ One can observe the positive MTC shown through lattice calculations again appears at the whole core level by comparison of Case 1 with Case 2, or by comparison of Cases 4 and 5. Overall, the agreement between the two codes gives confidence that the DRAGON/DONJON calculation scheme is giving sufficiently accurate results at zero burnup. 
Advanced Fuels for LWRs: FCM and Related Concepts FY 2012 Interim Report

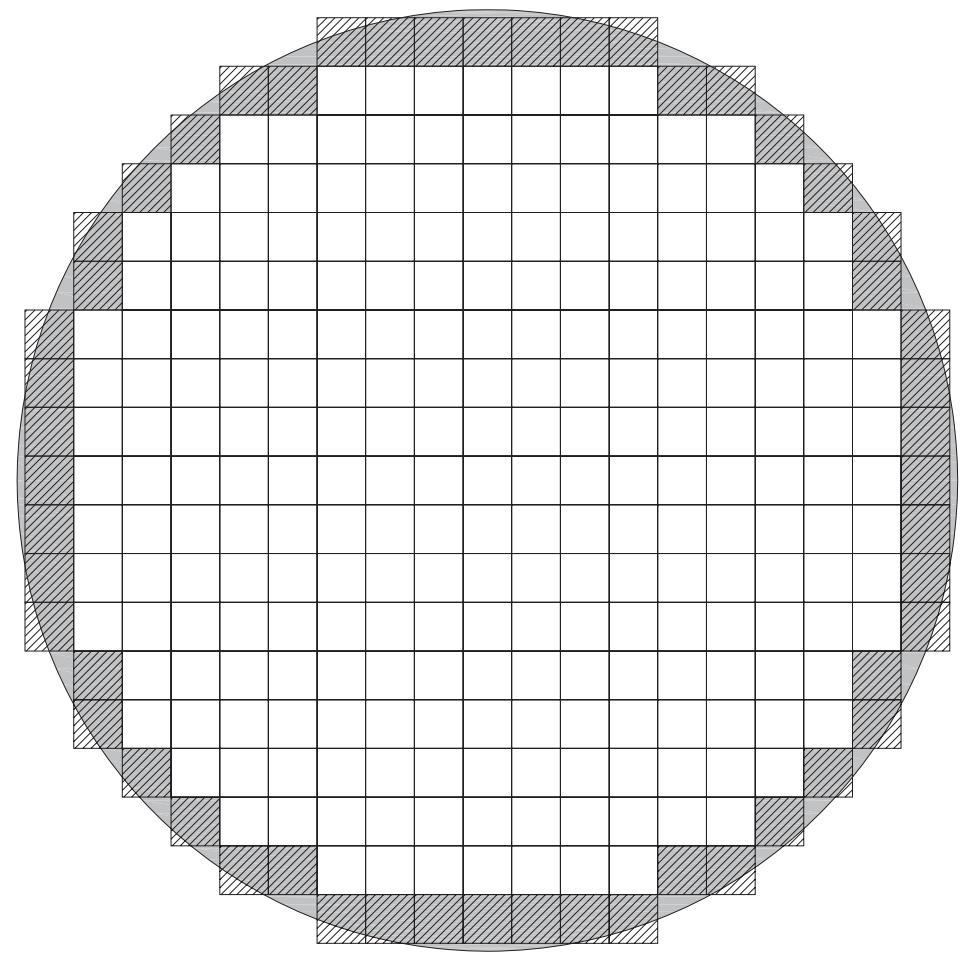

Figure 2-11. Diagram showing equivalent Cartesian representation (hashed) of reflector (shaded gray). 